\title{
Mechanical behavior of syntactic foams for deep sea thermally insulated pipeline. \\ D.Choqueuse ${ }^{1, a}$, P.Davies ${ }^{1, b}$, D.Perreux ${ }^{2, \mathrm{c}}$, L.Sohier ${ }^{3, \mathrm{~d}}, \mathrm{~J}-\mathrm{Y}$ Cognard $^{3, \mathrm{e}}$ \\ ${ }^{1}$ IFREMER, Brest Centre, F-29280 Plouzané, France \\ ${ }^{2}$ Ste Mahytec, 210 Avenue de Verdun, 39100, Dole, France \\ ${ }^{3}$ LBMS, ENSIETA -UBO, 2 rue F Verny, 29806 Brest, France \\ adominique.choqueuse@ifremer.fr, ${ }^{\mathrm{b}}$ peter.davies@ifremer.fr, 'dominique.perreux@mahytec.com, \\ d laurent.sohier@univ-brest.fr, ${ }^{\mathrm{e}}$ jean-yves.cognard@ensieta.fr
}

Keywords: syntactic foam, hydrostatic compression, shear test.

\begin{abstract}
.
Ultra Deep offshore oil exploitation (down to 3000 meters depth) presents new challenges to offshore engineering and operating companies. Flow assurance and particularly the selection of insulation materials to be applied to pipe lines are of primary importance, and are the focus of much industry interest for deepwater applications. Polymeric and composite materials, particularly syntactic foams, are now widely used for this application, so the understanding of their behavior under extreme conditions is essential. These materials, applied as a thick coating (up to $10-15 \mathrm{~cm}$ ), are subjected in service to:

- high hydrostatic compression (up to $30 \mathrm{MPa}$ )

- severe thermal gradients (from $4^{\circ} \mathrm{C}$ at the outer surface to $150^{\circ} \mathrm{C}$ at the inner wall),
\end{abstract}

and to high bending and shear stresses during installation. Damageable behavior of syntactic foam under service conditions has been observed previously [1] and may strongly affect the long term reliability of the system (loss of thermal properties). This study is a part of a larger project aiming to model the in-service behavior of these structures. For this purpose it is important to identify the constituent mechanical properties correctly $[2,3]$. A series of tests has been developed to address this point, which includes:

- hydrostatic compression

- shear loading using a modified Arcan fixture

This paper will describe the different test methods and present results obtained for different types of syntactic foams.

\section{Introduction.}

Syntactic foams are now widely used as passive thermal insulation material for deep sea pipeline and components (Figure 1). They are made by incorporating hollow glass microspheres $(150 \mu \mathrm{m}>$ $\varnothing>10 \mu \mathrm{m}$, wall thickness around $1.5 \mu \mathrm{m}$ ) in polymers (PU, PP, Epoxy ...). Their composition confers good performance in terms of thermal insulation and hydrostatic compression (nominally $0.18>\mathrm{k} \mathrm{W} /(\mathrm{m} . \mathrm{K})>0.12$ and $\max$ pressure $>30 \mathrm{MPa}$ ). They are applied using different manufacturing process including co extrusion, lateral extrusion, molding....During the lifetime of the structure (installation, in service, ...) high mechanical loading can be applied to the material and good 
knowledge of the mechanical response of such materials is required in order to guarantee long term reliability of the insulated structures
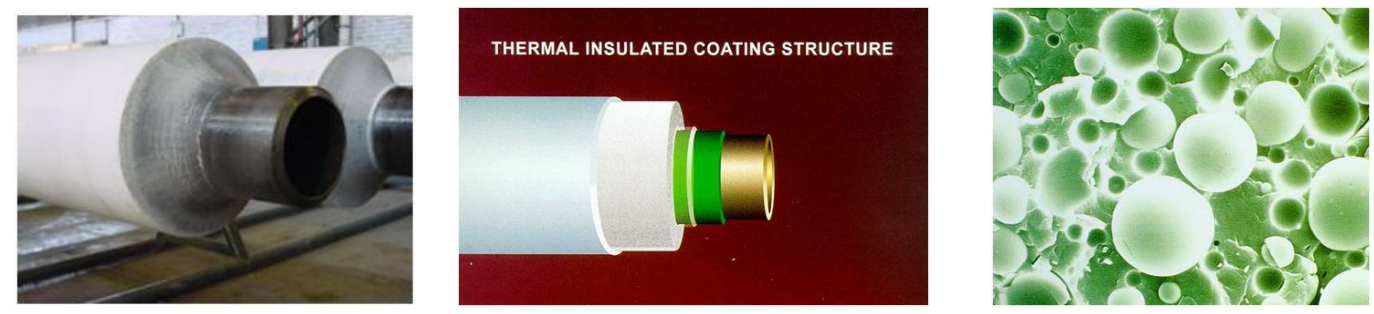

Figure 1 : Thermal insulation structure (doc Socotherm)

Uniaxial compression properties of syntactic foams have already been addressed by different authors $[4,5]$. In a recent experimental study [6] X ray microtomography has been used to visualize and describe the behavior of these materials during uniaxial loading and confined compression. However all these tests are polluted by edge effects, and a correct description of initial damage appears difficult. In order to model the behavior of the structure during its life time properly it is important to propose mechanical tests giving access to intrinsic properties of the material

\section{Hydrostatic compression}

Very few methods are available to determine the hydrostatic compression behavior of materials and "in house" tests are generally used to provide information. The principle is generally to follow the displacement of the piston of a cylinder in which the sample to be tested is placed. The pressure/piston displacement curve can provide a collapse pressure identified by a change of slope of the curve.

In order to improve this characterization Ifremer has developed a specific method based on the direct measurement of the buoyancy of a sample during pressure increase (Figure 2).
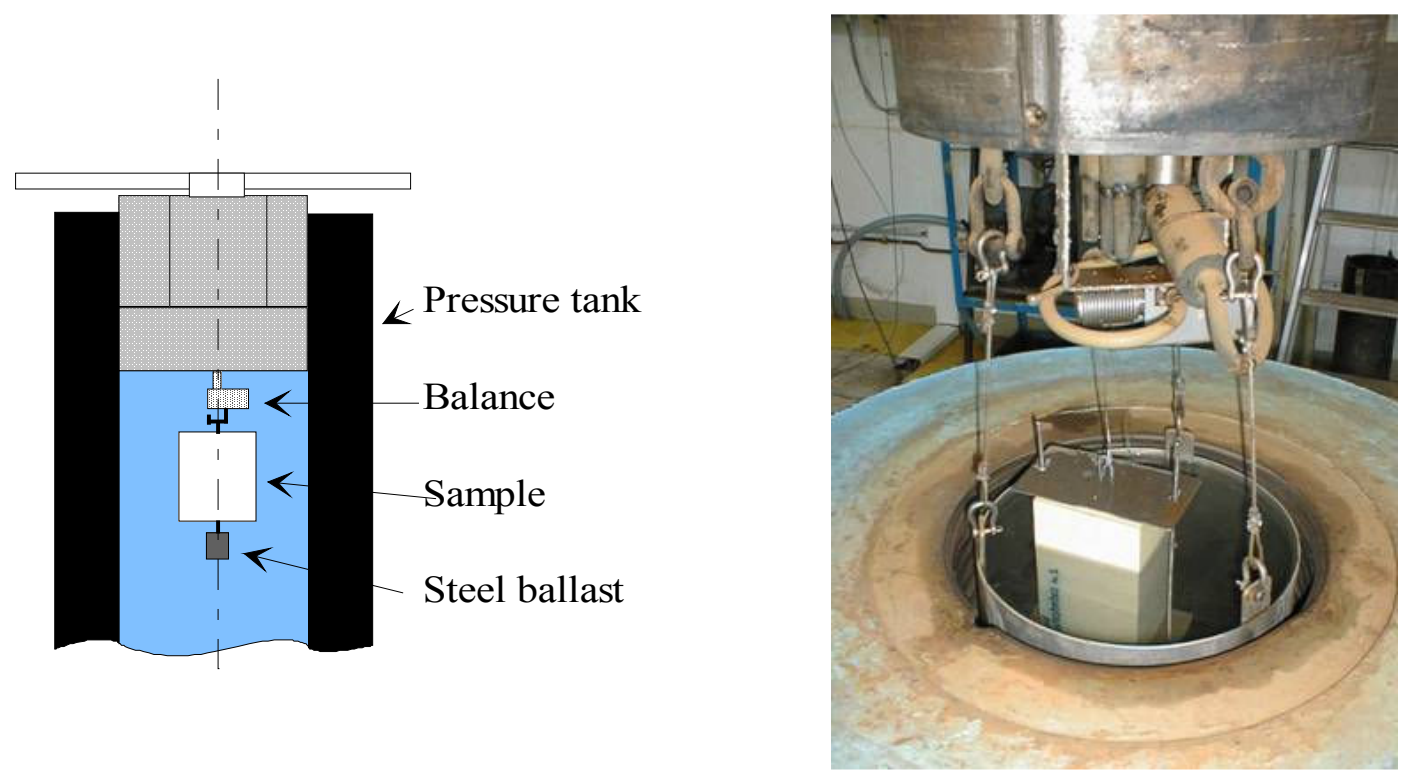

Figure 2 : Hydrostatic compression test

This test has been developed for materials with density lower than $1000 \mathrm{~kg} / \mathrm{m}^{3}$ but can be adapted to materials with higher specific gravity. It is based on the use of a weight sensor (balance: load range $1 \mathrm{~N}$ ) which can operate under high hyperbaric pressure (up to $100 \mathrm{MPa}$ ). 
In order to increase the sensitivity of the measurement the procedure consists of following the evolution of the buoyancy of both the sample and the steel ballast, and knowing the specific gravity of the material at atmospheric pressure it is possible to determine the specific gravity of the material versus the pressure. In addition, knowing the evolution of the density of water with pressure [7] it is possible to determine accurately, from the evolution of the buoyancy of the material, the evolution of the volume of the sample versus pressure and then to determine intrinsic parameters such as bulk modulus and collapse pressure.

A material sample, volume around $1 \mathrm{dm}^{3}$, is placed below the balance with steel ballast whose weight is calculated in order to give to the ensemble (sample + ballast) a small positive weight in water. All the system is placed in a hyperbaric tank and the pressure is increased by means of an electric pump.

Taking into account the accuracy of the system measurement and of the input data, the accuracy of results obtained for the evolution of buoyancy and bulk modulus can be evaluated : for a $1 \mathrm{dm}^{3}$ volume specimen, this is around $1 \%$.

Water uptake of samples during the test can affect the results for bulk modulus. However, the duration of testing, about 1 hour, leads to very little water ingress. Nevertheless systematic weighing of the sample after the test gives an indication of the quantity of water absorbed during the test, to check that it is related to surface absorption only.

Typical curves from the tests are reported below (Figure 3).
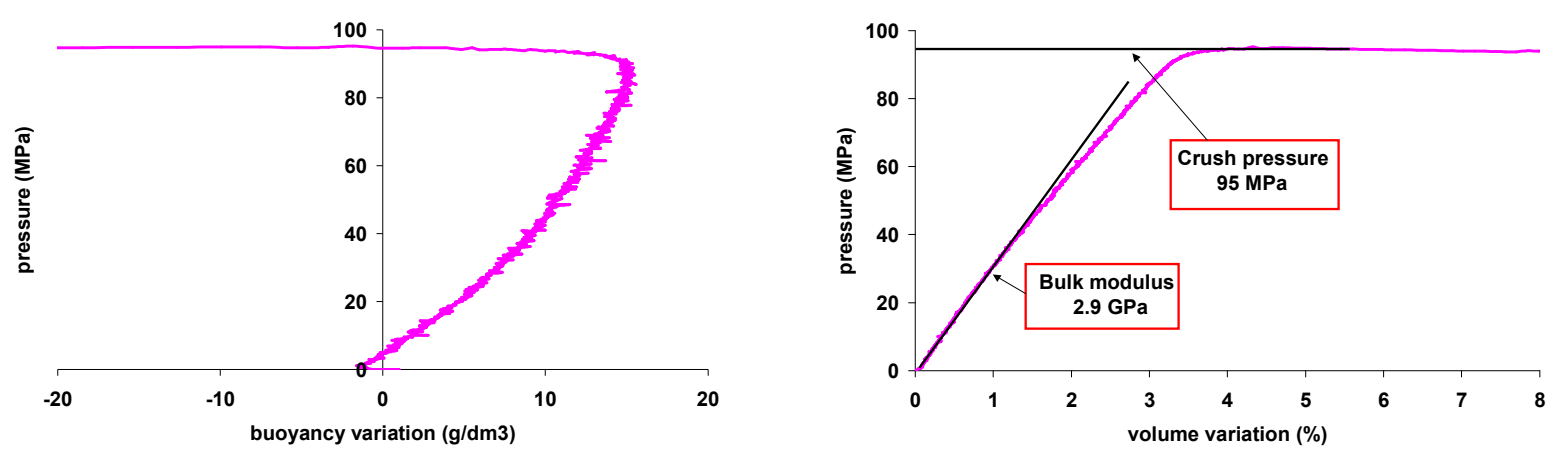

Figure 3: Hydrostatic compression behavior

The curve of variation of volume versus pressure gives access to the intrinsic mechanical behavior of the material. The global behavior of the materials can be characterized by a first linear elastic response, where the bulk modulus of the material is identified $(2.9 \mathrm{GPa})$, and the collapse pressure (95 MPa), called "crush pressure".

A comparison has been made between two materials, Mat A and Mat B, having the same grade of spheres and two different matrix polymers: a rigid matrix (epoxy), Mat A and a soft matrix (PU), Mat B.

It can be noted (Figure 4a) that the initial bulk modulus of the two materials is comparable and that the crush pressure of the material with rigid matrix is significantly higher than for the material with the soft matrix (90 MPa compared to $50 \mathrm{MPa}$ ). Up to $80 \%$ of the crush pressure the material with 
the rigid matrix presents an apparent linear elastic behavior, in strong contrast to the material with the soft matrix which presents a non linear behavior from the beginning of the test. The hydrostatic compression behavior appears to be strongly governed by the nature of matrix.

A study has been made on a material (Mat $\mathrm{C}$ : epoxy matrix) at different temperatures $\left(4^{\circ} \mathrm{C}, 50^{\circ} \mathrm{C}\right.$ and $100^{\circ} \mathrm{C}$ ) (Figure $4 \mathrm{~b}$ ). This shows a strong influence of the temperature. It can be assumed that the temperature, in terms of micromechanical behavior, mainly affects the behavior of the matrix.
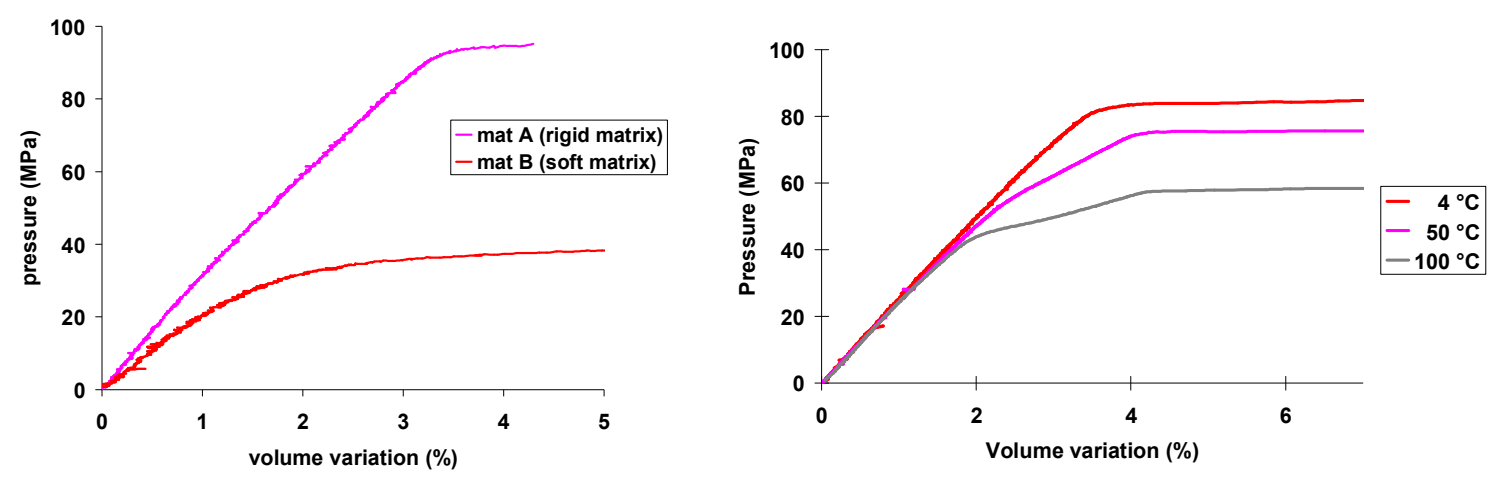

Figure 4: Hydrostatic compression behavior $a$ - effect of the matrix rigidity $b$ - effect of the temperature

\section{Shear test}

To complete the information provided by the hydrostatic compression test it is important to evaluate the shear behavior of the material. For this type of material different solutions have been envisaged: torsion tests on cylinders, Iosipescu test... In a first step, and taking into account the ease of sample preparation (difficulty to machine cylindrical samples) the Iosipescu test has been retained, and tests have been performed on materials A and B (Figure 5). Different material thicknesses (3 and $10 \mathrm{~mm}$ ) have been tested. These tests provide an apparent shear modulus, but for the rigid matrix the failure appears to be sudden while for soft matrix the strain is too high to be able to reach the failure.

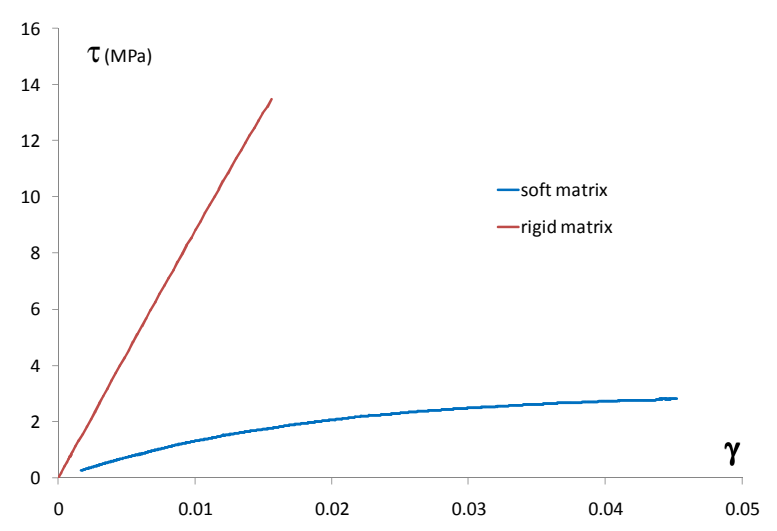

Figure 5: Iosipescu shear test results

In order to address properly non linearity and failure of these materials, which were clearly not obtained with the Iosipescu test, shear tests using the modified Arcan fixture have been evaluated, Figure 6. The Arcan test was initially developed [8] to produce uniform plane stress and a modified 
version has been used recently, associated with image analysis, to characterize bonded joints [9]. Different geometries of samples have been investigated and finally $0.5^{*} 7,6 * 66 \mathrm{~mm}^{3}$ specimen bonded on aluminium support have been selected in order to minimize the effect due to the appearance of normal stress.
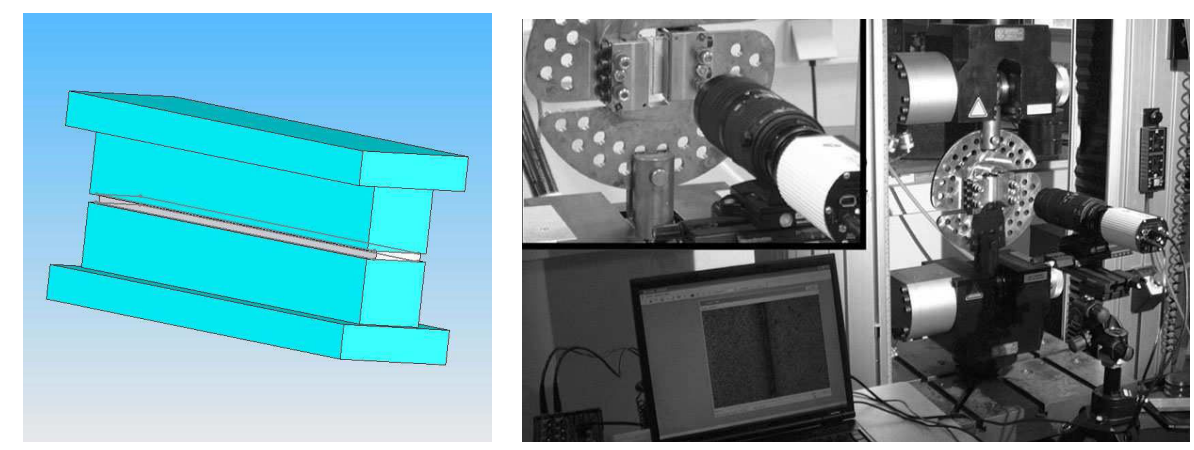

Figure 6: modified Arcan shear test set up

Non linear behavior of the material is shown (Figure 7). It can be noted that the response of the material can be observed right up to cracking initiation, noted around $120 \%$ strain for material B. The shear modulus obtained on material A (rigid matrix) is comparable ( $800 \mathrm{MPa}$ ) to the modulus obtained through the Iosipescu test whereas the results obtained on material B are significantly different.

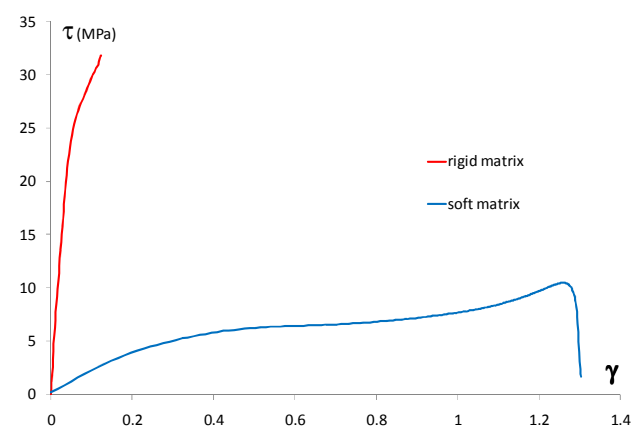

Figure 7: modified Arcan shear test - material behavior comparison

Tests were performed at different loading rates on material B (Figure 8). High sensitivity to loading rate is highlighted, which reveals a viscoelastic/ plastic behavior of the material.

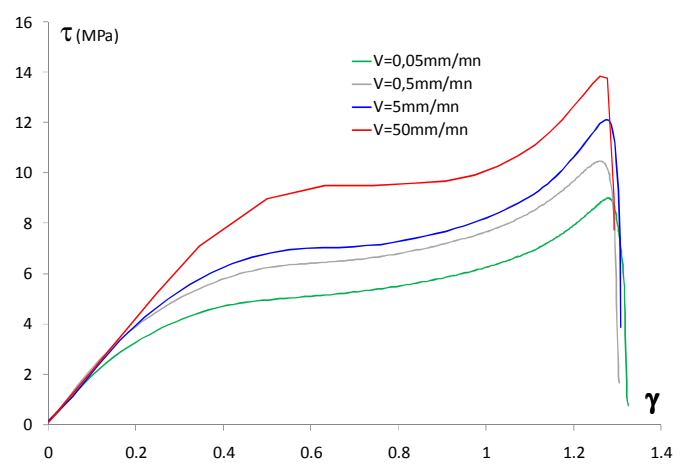

Figure 8: modified Arcan shear test - material B - effect of loading rate 


\section{Conclusions}

Syntactic foams exhibit complex mechanical behavior (damageable - visco - elasto-plastic behavior) and their characterization needs a careful experimental approach in order to obtain valid data.

Two types of tests are proposed in this paper.

- Hydrostatic compression test. These are based on the measurement of apparent buoyancy during pressure increase, gives pertinent data allowing characterization of the material.

- Shear tests. For these, improvement of the methods is still necessary, but an adapted Arcan fixture appears to be very promising.

This experimental study will be completed by multi axial tests using a specific device allowing mechanical loading to be performed under hydrostatic compression loading [10], in order to crosscorrelate the results obtained from the different test methods.

\section{References}

[1] F.Grosjean, N.Bouchonneau, D.Choqueuse, V.Sauvant-Moynot "Comprehensive analyses of syntactic foam behaviour in deep water environment”, J Mater Sci (2009) 44:1462-1468

[2] D.Choqueuse, et al, "Recent progress in analysis and Testing of insulation and buoyancy materials", Composite Materials and Structure for offshore application CMOO-4, 2004

[3] D.Choqueuse, et al, "Modeling approach for damageable mechanical behaviour of glass/polymer syntactic foams", Syntactic and Composite Foams II, 2007.

[4] N. Gupta, Kishore, E.Woldesenbet, S.Sankaran, et al, "Studies on compressive failure features in syntactic foam material", J Mater Sci (2001) 36:4485-4491

[5] M.Koopman, K.K. Chawla, B.Carlisle, "Microstructural failure modes in three-phase glass syntactic foams", J Mater Sci (2006) 41:4009-4014

[6] J.Adrien, E.Maire, N.Gimenez, V.Sauvant-Moynot, Experimental study of the compression behaviour of syntactic foams by in situ X-ray tomography, Acta Materialia 55 (2007) 16671679

[7] UNESCO, 1983, "Algorithms for computation of fundamental properties of seawater", Unesco technical papers in marine science

[8] M. Arcan , Z. Hashin, A. Voloshin "A method to produce uniform plane-stress states with application to fiber-reinforced materials. Experimental mechanics 18 (1978): 141-146

[9] P. Davies , L. Sohier b, J.-Y. Cognard, A. Bourmaud, D. Choqueuse, E. Rinnert, R. Créac'hcadec, "Influence of adhesive bond line thickness on joint strength", International Journal of Adhesion \& Adhesives 29 (2009) 724-736

[10] Cartié D, Davies P, Peleau M, Partridge I, "the influence of hydrostatic pressure on the interlaminar fracture toughness of carbon/epoxy composites", Composites Part B: Engineering Volume 37, Issues 4-5 , (2006), Pages 292-300 